\title{
Associated factors of secondary sex ratio of offspring in assisted reproductive technology: a cross-sectional study in Jilin Province, China
}

\author{
Mohan Wang, Xiangyin Liu, Han Zhang, Leilei Li, Ruizhi Liu, Hongguo Zhang and Yang Yu* (1)
}

\begin{abstract}
Background: The aim of this study was to determine the secondary sex ratio (SSR) of offspring in assisted reproduction technology (ART) in Jilin Province, China, and to analyse the influencing factors associated with SSR.

Methods: A cross-sectional study of 3833 babies including singletons and twins born to 2990 couples treated by ART between May 2011 and December 2018 was performed.

Results: The main outcomes of this study were that the SSR of ART babies in Jilin Province was $50.64 \%$ and the SSR was associated with fertilization methods $(p<0.05)$. Comparing to in vitro fertilization (IVF), intracytoplasmic sperm injection (ICSI) $(O R=0.808,95 \% \mathrm{Cl}: 0.681-0.958)$ decreased the percentage of male babies.

Conclusions: This study suggests that the SSR of ART births in Jilin Province was lower than the normal level and ICSI had a significant effect on SSR. Though we need more samples to study in the future, we still need to think about the impact of ICSI on SSR in ART.
\end{abstract}

Keywords: Secondary sex ratio, Intracytoplasmic sperm injection, Assisted reproduction technology

\section{Background}

Human sex ratio is an important indicator of the gender balance of men and women. It is influenced by many factors. The ratio after conception is the primary sex ratio (PSR). And the ratio at birth is the secondary sex ratio (SSR). SSR is significantly lower than PSR due to abortion and many other factors. The normal value of SSR is approximately 100 females to 105 males [1]. The stability of SSR is of great significance for maintaining social stability and promoting economic development.

With the rapid development of assisted reproduction technology (ART ), more and more test-tube babies were born by ART [2]. It may have an effect on SSR

\footnotetext{
* Correspondence: yuyang0351@126.com

Center of Reproductive Medicine, Center of Prenatal Diagnosis, the First Hospital, Jilin University, 71 Xinmin Street, Changchun, Jilin 130021, China
}

compared to natural pregnancy. Gametes and embryos were exposed to external factors during ART, which might be different from the influence of internal factors on the SSR under natural pregnancy.Scholars began to study which factors in the process of ART will affect the SSR [3]. Most studies had demonstrated that the SSR in test-tube babies was influenced by the use of intracytoplasmic sperm injection (ICSI). Although this was not a definite conclusion, related studies showed a trend that ICSI would decreased the SSR comparing to in vitro fertilization (IVF) [4, 5]. Some researchers specifically used systematic review to clarify that blastocyst stage transplantation might increase the SSR when it was compared with cleavage stage transplantation [4-6]. Other aspects, single or multiple births might also have an influence on the SSR [7]. In addition to this, paternal

(C) The Author(s). 2020 Open Access This article is licensed under a Creative Commons Attribution 4.0 International License, which permits use, sharing, adaptation, distribution and reproduction in any medium or format, as long as you give appropriate credit to the original author(s) and the source, provide a link to the Creative Commons licence, and indicate if changes were made. The images or other third party material in this article are included in the article's Creative Commons licence, unless indicated otherwise in a credit line to the material. If material is not included in the article's Creative Commons licence and your intended use is not permitted by statutory regulation or exceeds the permitted use, you will need to obtain permission directly from the copyright holder. To view a copy of this licence, visit http://creativecommons.org/licenses/by/4.0/ The Creative Commons Public Domain Dedication waiver (http://creativecommons.org/publicdomain/zero/1.0/) applies to the data made available in this article, unless otherwise stated in a credit line to the data. 
age, maternal age, smoking, even stress were the influencing factors of SSR [8-10]. Environmentalists drew a conclusion that SSR was low in areas with high air pollution through research [10]. Thus it could be seen, the factors that could influence the SSR were complex.

There had been lots of studies showing the SSRs brought by ART and exploring the influencing factors of the SSR. Jilin Province as a large province in northern China, there were no research on this type had been reported. We used the data one of the large reproductive centre in the province to enumerate the SSR and try to analyse the influencing factors of it. This study will put forward referable suggestions for maintaining the gender balance in Jilin Province.

\section{Methods}

\section{Study subjects}

The data was collected from Centre for Reproductive Medicine, First Hospital of Jilin University, Changchun, China. The study subjects included babies born to 2990 couple patients who performed ART from May 2011 to December 2018. Oocyte donation cycles, pre-implantation genetic diagnosis cycles and pre-implantation genetic screening were not included. Our subjects included singletons and twins. One male baby and one female baby twins were excluded when we performed logistic regression analyses. And for multi-cycle couples, we only included the first delivery cycle. The study had been approved by the ethics committee of the First Hospital of Jilin University. And written informed consent was obtained from each participant.

\section{Definitions and measurements}

SSR in this study was the ratio of male births to total births. The variables in the analyses included number of cycles, maternal age, paternal age, infertility duration, maternal BMI, infertility type, infertility factor, fertilization methods, embryo transfer morphology, embryo transfer stage and birth type. The number of cycles referred to the current cycle number of the patient's delivery. Infertility duration referred to the number of years of infertility without contraception. Above two variables were all divided into groups by class interval. And the class interval of maternal age group and paternal age group were 10 years old. The maternal BMI was divided into three groups according to the World Health Organization criteria. And birth type included singletons and twins two groups.

\section{Data analysis}

SPSS software ( Version 24.0, IBM SPSS, IBM Corp, Armonk, NY, USA ) was used to analyse the data. Univariate logistic regression analyses were performed to examine the correlations of various variables with SSR. Statistical significance was set to $p<0.10$. The significant variables were put into multivariable logistic regression

Table 1 SSRs of babies from different patients with ART and birth types

\begin{tabular}{|c|c|c|c|c|}
\hline & Total births & Male babies & Female babies & SSR(\%) \\
\hline \multicolumn{5}{|l|}{ Infertility type } \\
\hline Primary & 2674 & 1361 & 1313 & 50.90 \\
\hline Secondary & 1159 & 580 & 579 & 50.04 \\
\hline \multicolumn{5}{|l|}{ Infertility factor } \\
\hline Male & 1532 & 766 & 766 & 50.00 \\
\hline Female & 1462 & 747 & 715 & 51.09 \\
\hline Both male and female & 548 & 276 & 272 & 50.36 \\
\hline Unknown & 291 & 152 & 139 & 52.23 \\
\hline \multicolumn{5}{|l|}{ Fertilization method } \\
\hline IVF & 2290 & 1177 & 1113 & 51.40 \\
\hline ICSI & 1276 & 611 & 665 & 47.88 \\
\hline R-ICSI & 267 & 153 & 114 & 57.30 \\
\hline \multicolumn{5}{|c|}{ Embryo transfer morphology } \\
\hline Fresh & 834 & 430 & 404 & 51.56 \\
\hline Thawed & 2999 & 1511 & 1488 & 50.38 \\
\hline \multicolumn{5}{|l|}{ Birth type } \\
\hline Singletons & 2147 & 1076 & 1071 & 50.12 \\
\hline Twins & 1686 & 865 & 821 & 51.30 \\
\hline Total & 3833 & 1941 & 1892 & 50.64 \\
\hline
\end{tabular}


Table 2 Univariate logistic regression analyses of different variables with SSR

\begin{tabular}{|c|c|c|c|c|c|}
\hline Variables & Total births & Male babies & SSR(\%) & OR & $95 \% \mathrm{Cl}$ \\
\hline \multicolumn{6}{|l|}{ Number of cycles } \\
\hline $1 \sim 3$ & 2519 & 1272 & 50.50 & 1.000 & \\
\hline $4 \sim 6$ & 29 & 13 & 44.83 & 0.797 & $0.382-1.663$ \\
\hline \multicolumn{6}{|l|}{ Maternal age group } \\
\hline $20 \sim 29$ & 892 & 441 & 49.44 & 1.000 & \\
\hline $30 \sim 39$ & 1610 & 818 & 50.81 & 1.056 & $0.897-1.244$ \\
\hline$\geq 40$ & 46 & 26 & 56.52 & 1.329 & $0.731-2.417$ \\
\hline \multicolumn{6}{|l|}{ Paternal age group } \\
\hline $20 \sim 29$ & 660 & 326 & 49.39 & 1.000 & \\
\hline $30 \sim 39$ & 1661 & 839 & 50.51 & 1.046 & $0.873-1.25$ \\
\hline $40 \sim 49$ & 213 & 117 & 54.93 & 1.249 & $0.916-1.703$ \\
\hline $50 \sim 59$ & 14 & 3 & 21.43 & 0.279 & $0.077-1.011$ \\
\hline \multicolumn{6}{|l|}{ Infertility duration } \\
\hline $0 \sim 10$ & 2433 & 1222 & 50.23 & 1.000 & \\
\hline $11 \sim 20$ & 115 & 63 & 54.78 & 1.201 & $0.825-1.748$ \\
\hline \multicolumn{6}{|l|}{ Maternal BMI } \\
\hline $18.5 \sim 25$ & 1723 & 876 & 50.58 & 1.000 & \\
\hline$<18.5$ & 593 & 286 & 48.23 & 0.901 & $0.747-1.086$ \\
\hline$\geq 25$ & 232 & 123 & 53.02 & 1.091 & $0.829-1.436$ \\
\hline \multicolumn{6}{|l|}{ Infertility type } \\
\hline Primary & 1766 & 898 & 50.85 & 1.000 & \\
\hline Secondary & 782 & 387 & 49.49 & 0.947 & $0.800-1.121$ \\
\hline \multicolumn{6}{|l|}{ Infertility factor } \\
\hline Male & 987 & 483 & 48.94 & 1.000 & \\
\hline Female & 989 & 510 & 51.57 & 1.111 & $0.931-1.325$ \\
\hline Both male and female & 368 & 183 & 49.73 & 1.032 & $0.812-1.311$ \\
\hline Unknown & 204 & 109 & 53.43 & 1.197 & $0.885-1.619$ \\
\hline \multicolumn{6}{|l|}{ Fertilization method } \\
\hline IVF & 1544 & 800 & 51.81 & 1.000 & \\
\hline ICSI & 822 & 380 & 46.23 & 0.800 & $0.675-0.947$ \\
\hline $\mathrm{R}-|\mathrm{CS}|$ & 182 & 105 & 57.69 & 1.268 & $0.930-1.730$ \\
\hline \multicolumn{6}{|c|}{ Embryo transfer morphology } \\
\hline Fresh & 656 & 341 & 51.98 & 1.000 & \\
\hline Thawed & 1892 & 944 & 49.89 & 0.920 & $0.770-1.099$ \\
\hline \multicolumn{6}{|c|}{ Number of embryos transferred } \\
\hline 1 & 214 & 117 & 54.67 & 1.000 & \\
\hline 2 & 2288 & 1149 & 50.22 & 0.836 & $0.631-1.108$ \\
\hline 3 & 46 & 19 & 41.30 & 0.583 & $0.306-1.113$ \\
\hline \multicolumn{6}{|l|}{ Embryo transfer stage } \\
\hline Blastocyst & 551 & 283 & 51.36 & 1.000 & \\
\hline Cleavage stage & 1997 & 1002 & 50.18 & 0.954 & $0.790-1.152$ \\
\hline \multicolumn{6}{|l|}{ Birth type } \\
\hline Singletons & 2119 & 1060 & 50.02 & 1.000 & \\
\hline Twins & 429 & 225 & 52.45 & 1.102 & $0.895-1.356$ \\
\hline
\end{tabular}


Table 3 Multivariable logistic regression analysis of paternal age and fertilization methods with SSR

\begin{tabular}{llll}
\hline Variables & OR & $\mathbf{9 5 \% C l}$ & $\mathbf{P}$ \\
\hline Paternal age group & & & \\
$20 \sim 29$ & 1.000 & & \\
$30 \sim 39$ & 1.020 & $0.850-1.223$ & 0.833 \\
$40 \sim 49$ & 1.220 & $0.894-1.665$ & 0.209 \\
$50 \sim 59$ & 0.298 & $0.082-1.079$ & 0.065 \\
Fertilization methods & & & \\
IVF & 1.000 & & \\
ICSI & 0.808 & $0.681-0.958$ & 0.014 \\
R-ICSI & 1.261 & $0.924-1.721$ & 0.143 \\
\hline
\end{tabular}

to estimate the influencing factors for SSR. $P<0.05$ was considered to be significant.

\section{Results}

A total of 3833 babies were included from 2990 mothers in this study. There were 1941 male babies and $1892 \mathrm{fe}-$ male babies. The total SSR of the sample was $50.64 \%$. The SSR of singletons and twins were $50.12 \%$ and $51.30 \%$, respectively. The SSRs of different infertility types, factors, methods and embryo transfer morphologies were different (see Table 1).

Univariate logistic regression analyses showed that only paternal age and fertilization methods were associated with SSR $(p<0.10)$ in all variables .In terms of paternal age, the babies from highest paternal age group had a higher SSR than that from youngest age group $(p<0.10)$. And for fertilization methods, the SSR was significantly lower in ICSI group than IVF group $(p<0.05)$ ( Table 2$)$.

Table 3 showed the results of multivariate logistic regression analysis. Fertilization method was the only significant factor influencing SSR $(p<0.05)$. ICSI was associated with SSR (OR $=0.808,95 \% \mathrm{CI}$ : 0.681-0.958) and decreased the SSR comparing to IVF.

\section{Discussion}

The main findings of this study were as follows: the SSR of ART babies in Jilin Province was 50.64\%; SSR was associated with fertilization methods. And comparing to IVF, ICSI might decrease the percentage of male babies.

SSR is often used as an important indicator of population health and fertility. As far we know, the normal value of SSR is $51.22 \%$ [1]. Different from those of large sample studies, an analysis from the UK showed that the SSR of babies born through ART was 50.98\% [11]. It was lower than the normal value and approximated to ours. A study specifically on single embryo transfer revealed that the SSR of New Zealand and Australia were 51.3\% and $51.5 \%$, respectively [4]. They were all higher than the normal value. A Chinese large sample research [12] from 18 reproductive centers showed an SSR of $51.8 \%$, it was beyond the normal level. From our data result and the national, we could preliminarily conclude that ART might influence the SSR in China. Due to some factors such as large sample size gaps, research time, geographical differences or social demography structure, our result was different from the above studies. Whether the relatively lower SSR of babies born through ART in Jilin Province will balance the total SSR of the province, including through natural pregnancy, remains to be studied.

Although our results only showed an association between fertilization methods and SSR, this result was consistent with the results of other similar studies $[4,5,13$, 14]. The development of ICSI was facilitated when researchers focused on male infertility by considering sperm factors at the beginning of treatment for infertility [15]. As second-generation IVF technology, ICSI has been widely used worldwide. But researchers have never stopped discussing the safety of ICSI [16]. In the China's first large sample study [12] about SSR of ART babies, a preliminary analysis was conducted on the reasons why ICSI might reduce SSR. They thought that the patient's spermatogenic function was impaired, normally functioning sperm with Y chromosome was also reduced. However, other studies had shown that patients with normal spermatogenesis had reduced SSR after ICSI [4]. We analyzed the possible reason was although the best indication for ICSI targeted male factors such as azoospermia, some patients had ICSI because of non-male factors [15]. For example, those patients who had previously experienced failed fertilization with IVF. Therefore, the above different research results might have different conclusions, depending on what the indications for ART were. In this study, male factors accounted for the largest proportion of infertility factors. The number of patients undergoing ART for both male and female factors also accounted for a significant proportion. And we separated patients who had ICSI from rescue-ICSI. Rescue-ICSI were all performed after unsuccessful IVF that were for non-male factors. Unlike with ICSI alone, no effect on SSR was shown when compared to IVF. Most infertile men in our centre were patients with azoospermia or chromosomal abnormalities. Therefore, we tentatively concluded that the proportion of male babies born to ART patients who were solely due to male factors was lower than that of other factors.

There are some limitations in our study. Firstly, our sample size is relatively small. As a newly developed technology in Jilin Province in recent years, the sample size was limited when the gender of the offspring was excluded as one male and one female. What's more, the information we have collected is not comprehensive. We should collect information such as the test results of some reports from the parents, etc. This is the 
incomplete information caused by the incomplete electronic medical record system in the early stage. We think that in the future, with the gradual improvement of our system, we will analyse the impact on SSR from a more comprehensive perspective.

\section{Conclusions}

In conclusion, we found that the SSR of assisted reproductive technology births in Jilin Province was lower than the normal level through this study. And ICSI had a significant effect on SSR. The use of ICSI decreased SSR comparing to IVF. Although we need more samples to study in the future, we still need to think about the impact of ICSI on SSR in the assisted reproduction technology.

\section{Abbreviations}

SSR: Secondary sex ratio.; ART: Assisted reproduction technology:; IVF: In vitro fertilization.; ICSI: Intracytoplasmic sperm injection.; PSR: Primary sex ratio

\section{Acknowledgements}

Not applicable.

\section{Authors' contributions}

MHW, $Y Y, X Y L$ and $H Z$ designed and performed the study. MHW, XYL, HZ and LLL analyzed the data. MHW and XYL drafted the manuscript. MHW, LLL, RZL and HGZ participated in revising the draft of the manuscript. All authors approved the final version of the paper for submission.

\section{Funding}

This study was supported by Finance Department Health Special Project of Jilin Province, China (JLSCZD2019-022). The funding body was not involved in the design of the study, the collection, analysis, interpretation of data or in writing the manuscript.

\section{Availability of data and materials}

The data used in this study is not available for public view, but available from the corresponding author upon reasonable request.

\section{Ethics approval and consent to participate}

The study was approved by the Ethics Committee of the First Hospital of Jilin University (2020 - 398). And written informed consent was obtained from each participant.

\section{Consent for publication}

Not applicable.

\section{Competing interests}

All authors declare that they have no conflicts of interest.

Received: 27 May 2020 Accepted: 28 October 2020

Published online: 04 November 2020

\section{References}

1. James WH. Hypotheses on the stability and variation of human sex ratios at birth. J Theor Biol. 2012;310:183-6.

2. Kissin DM, Jamieson DJ, Barfield WD. Monitoring health outcomes of assisted reproductive technology. N Engl J Med. 2014;371(1):91-3.

3. Orzack SH, Stubblefield JW, Akmaev VR, Colls P, Munné S, Scholl T, Steinsaltz $D$, Zuckerman JE. The human sex ratio from conception to birth. Proc Natl Acad Sci USA. 2015;112(16):E2102-11.

4. Dean JH, Chapman MG, Sullivan EA. The effect on human sex ratio at birth by assisted reproductive technology (ART) procedures-an assessment of babies born following single embryo transfers, Australia and New Zealand, 2002-2006. BJOG: an international journal of obstetrics gynaecology. 2010; 117(13):1628-34
5. Luke B, Brown MB, Grainger DA, Baker VL, Ginsburg E, Stern JE. The sex ratio of singleton offspring in assisted-conception pregnancies. Fertility sterility. 2009;92(5):1579-85.

6. Milki AA, Jun SH, Hinckley MD, Westphal LW, Giudice LC, Behr B. Comparison of the sex ratio with blastocyst transfer and cleavage stage transfer. J Assist Reprod Genet. 2003;20(8):323-6.

7. Chen M, Du J, Zhao J, Lv H, Wang Y, Chen X, Zhang J, Hu L, Jin G, Shen H, et al. The sex ratio of singleton and twin delivery offspring in assisted reproductive technology in China. Scientific reports. 2017;7(1):7754.

8. Rueness J, Vatten L, Eskild A. The human sex ratio: effects of maternal age. Human reproduction (Oxford England). 2012;27(1):283-7.

9. Suzuki K, Yamagata Z, Kawado M, Hashimoto S. Effects of the Great East Japan Earthquake on Secondary Sex Ratio and Perinatal Outcomes. Journal of epidemiology. 2016;26(2):76-83.

10. Terrell ML, Hartnett KP, Marcus M. Can environmental or occupational hazards alter the sex ratio at birth? A systematic review. Emerging health threats journal. 2011:4:7109.

11. Supramaniam PR, Mittal M, Ohuma EO, Lim LN, McVeigh E, Granne I, Becker CM. Secondary sex ratio in assisted reproduction: an analysis of 1376454 treatment cycles performed in the UK. Human reproduction open. 2019; 2019(4):hoz020.

12. Bu Z, Chen ZJ, Huang G, Zhang H, Wu Q, Ma Y, Shi J, Xu Y, Zhang S, Zhang $C$, et al. Live birth sex ratio after in vitro fertilization and embryo transfer in China-an analysis of 121,247 babies from 18 centers. PloS one. 2014;9(11): e113522.

13. Bonduelle M, Liebaers I, Deketelaere V, Derde MP, Camus M, Devroey P, Van Steirteghem A. Neonatal data on a cohort of 2889 infants born after ICSI (1991-1999) and of 2995 infants born after IVF (1983-1999). Human reproduction (Oxford England). 2002;17(3):671-94.

14. Hentemann MA, Briskemyr $\mathrm{S}$, Bertheussen K. Blastocyst transfer and gender: IVF versus ICSI. J Assist Reprod Genet. 2009;26(8):433-6.

15. O'Neill CL, Chow S, Rosenwaks Z, Palermo GD. Development of ICSI. Reproduction. 2018;156(1):F51-f58.

16. Gleicher N. Safety issues in assisted reproduction technology. A rebuttal. Human reproduction (Oxford England). 2003;18(9):1765-6.

\section{Publisher's Note}

Springer Nature remains neutral with regard to jurisdictional claims in published maps and institutional affiliations.
Ready to submit your research? Choose BMC and benefit from:
- fast, convenient online submission
- thorough peer review by experienced researchers in your field
- rapid publication on acceptance
- support for research data, including large and complex data types
- gold Open Access which fosters wider collaboration and increased citations
- maximum visibility for your research: over $100 \mathrm{M}$ website views per year
At BMC, research is always in progress.
Learn more biomedcentral.com/submissions 